\title{
Research on Dust Concentration Changing Regularities in Coal Releasing Operation of Fully Mechanized Caving Faces and Dust Reduction Technology
}

\author{
Lirong $\mathrm{Wu}$ \\ College of Mining and Safety \\ Engineering \\ Shandong University of Science and \\ Technology \\ Qingdao, China \\ Lrwu1981@163.com
}

\author{
Weimin Cheng \\ College of Mining and Safety \\ Engineering \\ Shandong University of Science and \\ Technology \\ Qingdao, China \\ Chengmw@163.com
}

\author{
Gang Zhou \\ College of Mining and Safety \\ Engineering \\ Shandong University of Science and \\ Technology \\ Qingdao, China \\ ahsdzhougang@163.com
}

Abstract-Getting the changing law of dust concentration in fully mechanized coal caving face and taking specific measures can ensure the safety and health of workers. The dust migration rule of coal releasing process under different conditions was simulated by the software of FLUENT. The simulated result matches well with the related survey data. Considering the factors of velocity and mass flow quantity, the dust distribution function in the process of coal releasing was studied. According to the characteristics of the spray nozzle and the spray drop test, the nozzle is optimized. Combining the characteristics of dust generation in coal releasing and spray characteristics, based on the theory of negative pressure secondary dust suppression, the dust suppression device is developed and used in 3Top1110 coal mining face of Gao zhuang coal mine. Through the analysis of dust concentration changes after using the dust suppression device, the total dust and respirable dust removal rate was $79 \% \sim 88 \%$, and $56 \%$ $65 \%$ respectively. It is seen that the dust concentration of the working face was significantly decreased.

Keywords-coal releasing operation; gas-solid two-phase flow; dust concentration; spray dust suppression

\section{INTRODUCTION}

As the coal dusts spread under the gravity, inertia force and air flow, the concentration \& particle size change in different points, it is difficult to reduce the dust concentration effectively. Knowing the dust migration rule, the dust trajectory of different diameter dusts, and taking the take targeted measures are useful to reduce the dust concentration effectively.

Nowadays many experts have studied the coal dust concentration changeable rule and migration regularity of coal mining by numerical simulation( Yang, 2001; Liu, 2007; Zhao, 2008; Niu, 2008; Wei, 2009; Du, 2010; Zhou, 2010; Niu, 2010; Cheng, 2011; Wang, 2011; Liao,2012; Chen, 2012; Jiang, 2012; Chen, 2013; Jiang, 2013;Yao, 2015; Tan, 2015; Zheng, 2015; Zhou, 2016; Nie, 2017; Zhang, 2017) ${ }^{[1-}$ ${ }^{21]}$. The numerical simulation about coal dust mainly focuses on the dust concentration changeable rule at one moment, without considering the influence of air ventilation and mass flow. Also, the dust migration rule of different particle size is scarce.
The application of spraying technology in fully mechanized coal caving workface aims to reduce the coal dust concentration. Nowadays the present research mainly concentrates on the design of dust removing devices of spray(Liu, 2004; Zhai, 2007; Liu, 2007; Li, 2008; Niu, 2008;

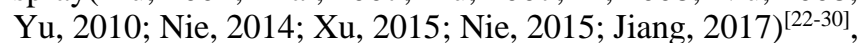
and coal dust reduction theories \& technology(Guo, 2004; Wang, 2005; Zhou, 2009; Xie, 2010; Song, 2010; Wang, 2015; Qin, 2017) ${ }^{[31-37]}$.

At present, the hydraulic support spray dust suppression measures have been applied in most of the fully mechanized caving faces. As the choosing of nozzles and nozzles' position setting have great randomness, it can't catch the dust effectively and hinder the dust concentration reduction effect.

This paper first analyzes the dust migration rule theoretically. Then the dust concentration changeable rule when the air speed and flow mass change has been simulated by the software of Fluent, and the fitting function of dust concentration has been studied. Based on the nozzle jet characteristic experiment and spray dust experiment, the preferable nozzles have been selected. Combining the dust production regulation and nozzle characteristics, the negative pressure re-secondary dust suppression devices of spray in fully mechanized caving faces are designed and applied.

\section{THEORETICAL STUDY OF DUST MIGRATION RULE}

In fully mechanized caving faces the gas flow control equations apply the three-dimensional steady incompressible Navier-Stokes equation. Turbulent flow model uses the $k-\varepsilon$ double equation model, in which the momentum transfer is considered and the heat passage is neglected ${ }^{[1,8-10]}$. Continuous equation:

$$
\frac{\partial}{\partial x_{i}}\left(\rho u_{i}\right)=0
$$

Equation of motion:

$$
\frac{\partial c}{\partial x_{i}}\left(\rho u_{i} u_{j}\right)=-\frac{\partial p}{\partial x_{i}}+\frac{\partial}{\partial x_{i}}\left[\left(\mu+\mu_{t}\right)\left(\frac{\partial u_{j}}{\partial x_{i}}+\frac{\partial u_{i}}{\partial x_{j}}\right)\right](2)
$$

$k$ equation: 


$$
\frac{\partial}{\partial x_{i}}\left(\rho u_{i} k\right)=\frac{\partial}{\partial x_{i}}\left[\left(\mu+\frac{\mu_{t}}{\sigma_{k}}\right) \frac{\partial k}{\partial x_{i}}\right]+G_{k}-\rho \varepsilon
$$

$\varepsilon$ equation:

$$
\begin{gathered}
\frac{\partial}{\partial x_{i}}\left(\rho u_{i} \varepsilon\right)=\frac{\partial}{\partial x_{i}}\left[\left(\mu+\frac{\mu_{t}}{\sigma_{\varepsilon}}\right) \frac{\partial k}{\partial x_{i}}\right]+\frac{C_{\varepsilon 1} \varepsilon}{k} G_{k} \varepsilon^{2}-C_{\varepsilon 2} \rho \frac{\varepsilon^{2}}{k} \\
\mu_{t}=C_{\mu} \rho \frac{k^{2}}{\varepsilon} \\
G_{K}=\mu_{t} \frac{\partial u_{j}}{\partial x_{i}}\left(\frac{\partial u_{j}}{\partial x_{i}}+\frac{\partial u_{i}}{\partial x_{j}}\right)
\end{gathered}
$$

$G_{K}$-the turbulent kinetic energy change rate generated by Shear force changes;

$k$-turbulent kinetic energy, $\mathrm{m}^{2} / \mathrm{s}^{2}$;

$\varepsilon$ - turbulent dissipation rate, $\mathrm{m}^{2} / \mathrm{s}^{3}$;

$\mu$ _Laminar viscous coefficient, Pa.s;

$\mu_{t}$-Turbulent viscosity coefficient, $\mathrm{Pa} \cdot \mathrm{s}$;

$p$-The turbulence of effective pressure, $\mathrm{Pa}$;

$\rho$ - Gas density, $\mathrm{kg} / \mathrm{m}^{3}$;

$x_{i}$-Coordinate in the direction of $\mathrm{x}, \mathrm{y}, \mathrm{z}, \mathrm{m}$;

$\mu_{i}-$ Ventilation of fluid in the direction of $\mathrm{x}, \mathrm{y}, \mathrm{z}$, $\mathrm{m} / \mathrm{s}$;

$C_{\varepsilon 1}, C_{\varepsilon 2}, C_{\mu}, \sigma_{\varepsilon}, \sigma_{k} \quad$ - Constant. Taking $1.44 、 1.92 、 0.09 、 1.3 、 1.0$ successively。

The particle motion equation is solved by the integral operation in discrete time steps. And the movement track is as follows:

$$
\frac{d x}{d t}=u_{p}
$$

The velocity of particles on each position of the particle orbit can be got by the integral equation. By integral along different coordinates, particle trajectories can be obtained in the three-dimensional space.

\section{THE NUMERICAL SIMULATION AND ANALYSES OF DUST CONCENTRATION CHANGING REGULARITIES IN FULLY MECHANIZED CAVING FACES}

\section{A. THE NUMERICAL SIMULATION OF DUST CONCENTRATION CHANGING REGULARITIES IN FULLY MECHANIZED CAVING FACES}

Taking the 3top1110 working face in Gao zhuang coal mine as the object of study, the rectangular region is made with the length, width and height of $20.0 \mathrm{~m}, 10.0 \mathrm{~m}$ and $3.0 \mathrm{~m}$ by the software of Gambit2.4.0. And the dust concentration changing regularities are simulated by the software of Fluent6.3.26.

In simulating the process of coal caving, dust source is located close to the gob side and lies in the fourth support bracket from the direction of air intake $(x=2.6 z=3)$, with the distance of $2 \mathrm{~m}$ to the working face floor. With the generation of 80 particles, the trajectory of dust particles is shown in Fig.1.

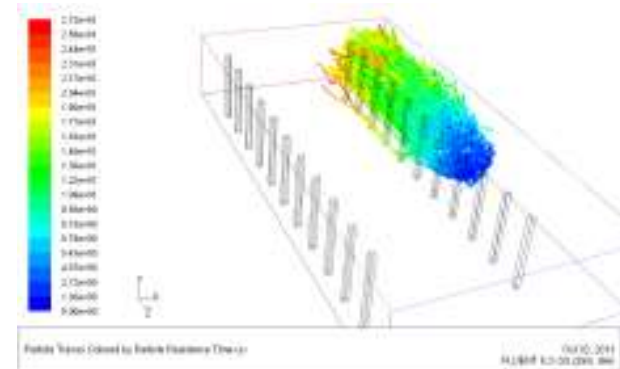

Fig. 1 The dust particle traces diagram in coal releasing operation

From the Fig.1, it can be seen that the dusts generated in the process of coal caving move downward under the action of gravity, toward the outlet under the influence of ventilation, and laterally in the direction of $\mathrm{X}$ axis as the result of collision effect among dust particles.

Research on the variation law of dust concentration under different wind speeds and dust mass flow rate.

\section{(1)Different wind speeds}

When the maximum velocity of inlet section was $0.25 \mathrm{~m}$ $/ \mathrm{s}, 1.0 \mathrm{~m} / \mathrm{s}$ and $2.0 \mathrm{~m} / \mathrm{s}$ and $3.0 \mathrm{~m} / \mathrm{s}, 4.0 \mathrm{~m}$ specifically, dust mass flow rate is $3.5 \mathrm{~kg} / \mathrm{s}$, dust concentration in the direction of $\mathrm{Z}$ axis direction, $7.6 \mathrm{~m}$ away from the coal wall, $1.5 \mathrm{~m}$ height was obtained by calculation and shown in Fig.2.

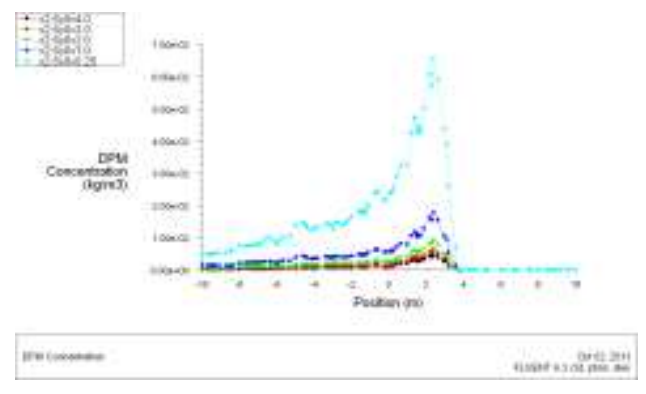

Fig.2 The dust concentration variation diagram in coal releasing operation

From Fig.2 it is shown that when the wind speed changes, the trend of dust concentration along the z-axis direction is consistent, the biggest dust concentration appears almost at the same point, and the dust concentration in the same position increases with the decreases of wind speed. Due to the point $7.6 \mathrm{~m}$ away from the coal wall is in the central area of the turbulent flow, it is influenced by wind more largely. When the wind speed changes from $0.25 \mathrm{~m} / \mathrm{s}$ to $1.0 \mathrm{~m} / \mathrm{s}$, dust concentration decreases considerably, and from $1.0 \mathrm{~m} / \mathrm{s}$ to $2.0 \mathrm{~m} / \mathrm{s}, 2.0 \mathrm{~m} / \mathrm{s}$ to $3.0 \mathrm{~m} / \mathrm{s}$, dust concentration decreases gradually. When the wind speed changes from $3.0 \mathrm{~m} / \mathrm{s}$ to 4.0 $\mathrm{m} / \mathrm{s}$, due to the effect of floating dust it changes little. Therefore, the optimum velocity is $3 \mathrm{~m} / \mathrm{s}$.

When the maximum wind speed is $0.25 \mathrm{~m} / \mathrm{s}$, the mass flow rate of dust source is $3.5 \mathrm{~kg} / \mathrm{s}, 2 \mathrm{~kg} / \mathrm{s}, 0.5 \mathrm{~kg} / \mathrm{s}, 0.25 \mathrm{~kg} / \mathrm{s}$, dust concentration in the direction of $\mathrm{Z}$ axis direction, $7.6 \mathrm{~m}$ away from the coal wall, $1.5 \mathrm{~m}$ height was obtained by calculation and shown in Fig.3. 


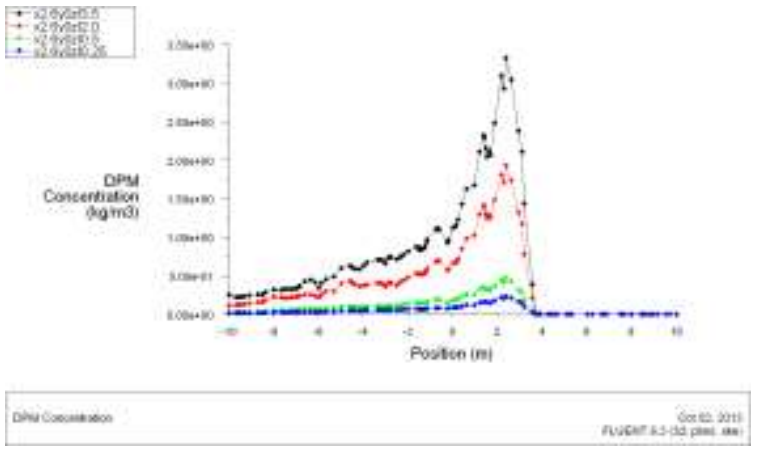

Fig.3 The dust concentration variation diagram in coal releasing operation

From Fig. 3 it is shown that when the mass flow rate changes, dust concentration changing tendency along the $\mathrm{Z}$ axis direction are basically the same, the location with the biggest dust concentration value has little difference, the dust concentration at the same position increases with the mass flow rate increases. The dust concentration with the distance of $7.6 \mathrm{~m}$ away from the coal wall and $1.5 \mathrm{~m}$ height from the ground is linear with the mass flow of the dust source. Therefore, reducing the amount of dust is the key to reduce the concentration of dust.

\section{B. THE ANALYSIS OF DUST CONCENTRATION VARIATIONAL RULES}

Taking the the dust concentration of 3top1110 fully mechanized top coal caving working face as the research object, the dust concentration distribution curve of field sampling is compared with the one of numerical simulation, which is shown in Fig.4.

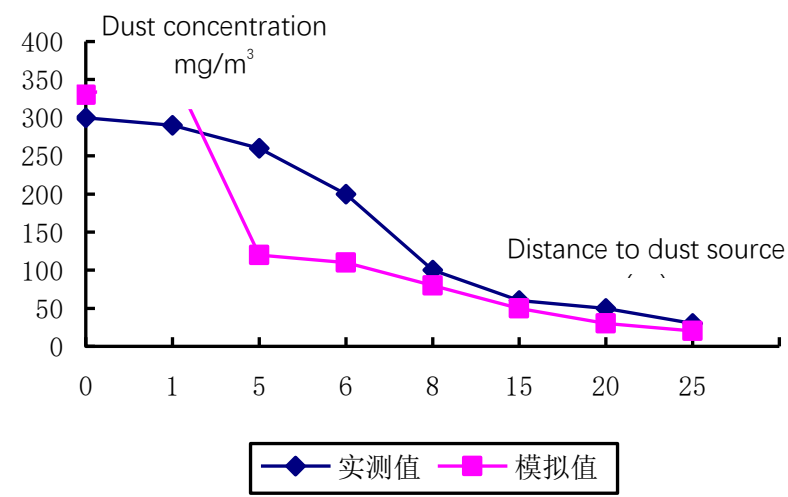

Fig.4 The comparison of simulated and measured dust concentration value in coal releasing operation

Due to some errors in coal dust sampling and determination, and simplification in simulation, certain deviation exists in coal dust concentration measured value and simulation one From Fig.4 it shows that both the overall trends are consistent.

The dust concentration data in numerical simulation are exported and dealt with. As it is difficult to use one function to fit the changes of dust concentration, the fitting function of different stages can be got. The functions about dust concentration of positions $7.6 \mathrm{~m}$ away from coal wall and $1.5 \mathrm{~m}$ height from ground include two functions. One is about the dusts $2.6 \mathrm{~m}$ range, and the other is $2.6 \mathrm{~m}$ out of range.

$$
\text { When } \begin{aligned}
-0.5 \leq x & <2.6, \\
y & =-108.26 x^{2}+255.41 x+194.72
\end{aligned}
$$

When $2.6 \leq x<13$,

$$
y=211.3 e^{-0.2427 x}
$$

The $R^{2}$ distribution of the fitting function is 0.9743 and 0.9458 , which are close to 1 and the fitting effect is good. The above fitting functions are based on the wind speed of $2 \mathrm{~m} \mathrm{/} \mathrm{s}$, and dust source mass flow rate of $0.002 \mathrm{~kg} / \mathrm{s}$, simulation is obtained by fitting the data. Therefore, in the actual situation, when the wind speed and dust source mass flow rate change, the fitting function can be adjusted on the basis of formula(8), (9).

When the wind speed changes from $0.25 \mathrm{~m} / \mathrm{s}$ to $1.0 \mathrm{~m} /$ $\mathrm{s}, 2.0 \mathrm{~m} / \mathrm{s}, 3.0 \mathrm{~m} / \mathrm{s} 4.0 \mathrm{~m} / \mathrm{s}$, dust concentrations of positions which are $7.6 \mathrm{~m}$ away from coal wall and $1.5 \mathrm{~m}$ height from ground are dealt with. Then the fitting function between dust concentration and velocity is got, which is shown in formula(10).

$$
y=8718.7 v^{-0.9697}
$$

When the mass flow rate of dust source changes from $0.25 \mathrm{~kg} / \mathrm{s}$ to $0.5 \mathrm{~kg} / \mathrm{s} 、 2.0 \mathrm{~kg} / \mathrm{s} 、 3.5 \mathrm{~kg} / \mathrm{s}$, dust concentrations of positions which are $7.6 \mathrm{~m}$ away from coal wall and $1.5 \mathrm{~m}$ height from ground are analyzed. Then the fitting function between dust concentration and mass flow rate of dust source is got, which is shown in formula(11).

$$
y=163488 n+11016
$$

The $R^{2}$ distribution of the fitting function is 0.9998 and 0.9986 , which are close to 1 . It shows that the fitting effect is good.

According to the dust concentration variation rule based on changes of air velocity and mass flux of the coal dust in the coal discharge operation, the adjusted fitting functions are shown in formula (12),(13).

$$
\begin{aligned}
& \text { When }-0.5 \leq x<2.6 \\
& y=\left(\frac{v}{2}\right)^{-0.9697}(14.4 n+0.97)\left(-108.26 x^{2}+255.41 x+194.72\right)
\end{aligned}
$$

When $2.6 \leq x<13$,

$$
y=211.3\left(\frac{v}{2}\right)^{-0.9697}(14.4 n+0.97) e^{-0.2427 x}
$$

Where $\mathrm{n}-$ mass flow rate of dust source, $\mathrm{kg} / \mathrm{s}$;

$\mathrm{v}$ - the average velocity in inlet section, $\mathrm{m} / \mathrm{s}$.

By formula (12), (13) dust concentration in different position under different wind speeds and different dust source mass flow rates can be got, which is the foundation for further adopting the measures of reducing dust concentration.

At the same time, for other fully mechanized caving face, if the boundary condition, the coal caving technology and the hydraulic support model are similar, the corresponding position dust concentration can also be got based on the formula (12), (13).

\section{OPTIMIZATION OF NOZZLES}

To choose the suitable nozzles used in dust depression, 8 ones are selected based on the investigation and their jet 
characteristics such as atomizing angle, range, flow, mist flow field shape, and droplet density, et al. They are numbered for the nozzle 1 to nozzle 8 .

Experiment of nozzle jet characteristics is done. According to the experimental results of the nozzle jet characteristics, with the increase of spray pressure, the D0.1, D0.5, D0.9, D32 and D43 particle sizes of 8 nozzles decreased. The smaller the nozzle droplet diameter, the better the atomizing effect of nozzles, and the stronger the ability to capture respirable dust. Considering spray equipment can tolerate $8 \mathrm{Mpa}$ water pressure, the water pressure of $8 \mathrm{Mpa}$ are adopted, under which each nozzle droplet diameter can reach the minimum in experiment. In experiment the nozzle 8 has the best atomization effect. The percentage of respirable dust being captured of 8 nozzles under the water pressure of $8 \mathrm{Mpa}$ is shown in Table1. The routine atomization parameters are summarized in Table 2.

TABLE1 THE PERCENTAGE of RESPIRABLE DUST BEING CAPTURE of 8 NOZZLES UNDER THE WATER PRESSURE OF 8MPA

\begin{tabular}{|c|c|c|c|c|c|c|c|c|}
\hline $\begin{array}{r}\text { Nozzle } \\
\text { Parameter }\end{array}$ & 1 & 2 & 3 & 4 & 5 & 6 & 7 & 8 \\
\hline Spray & 121.8 & 98.9 & 59.1 & 55.5 & 75.8 & 69.2 & 68.3 & 73.6 \\
\hline Effective & 4.4 & 5.3 & 5.2 & 5.3 & 4.3 & 4.7 & 5.2 & 5.3 \\
\hline Flow & 7.66 & 8.50 & 7.66 & 9.12 & 6.67 & 6.86 & 8.75 & 7.07 \\
\hline
\end{tabular}

TABLE 2 THE ROUTINE ATOMIZATION PARAMETERS OF 8 NOZZLES UNDER THE WATER PRESSURE OF 8MPA

\begin{tabular}{|c|c|c|c|c|c|c|c|c|}
\hline Nozzle & 1 & 2 & 3 & 4 & 5 & 6 & 7 & 8 \\
\hline Pressure & $\%$ & $\%$ & $\%$ & $\%$ & $\%$ & $\%$ & $\%$ & $\%$ \\
\hline $8 \mathrm{Mpa}$ & 84.51 & 90.73 & 62.95 & 62.02 & 77.11 & 91.13 & 86.44 & 91.36 \\
\hline
\end{tabular}

From Table 1, 2, it is can be seen that with the increase of spray pressure, the atomization parameters of nozzles decrease and the atomization effect is improved in different degrees. Because the mist flow shape of nozzle 2 and nozzle 1 is sector and the area is small, the dust removal effect is relatively poor in the fully mechanized caving face. Therefore in $8 \mathrm{Mpa}$ pressure the atomization effect of nozzle 3 nozzle 8 was studied. According to the droplet particle size data such as d0.1, d0.5, d0.9, D32, d43 and best dust collected particle size of respirable dust, nozzle $3 \sim$ nozzle 8 are divided into three categories based on the atomization effect. Nozzle 6 and nozzle 8 belong to the first class and have the best atomizing effect. Nozzle 8's atomization quality indexes have the better comprehensive effect and the percentage of respirable dust being captured was more than $91 \%$. The atomizing angle of nozzle8 is greater than that of nozzle 6, nozzle range is greater, and flow is slightly larger. Nozzle 5 and 7 are the second class and have the second atomization effect. The atomizing angle of nozzle 5 is 75.8 degrees and has the maximum atomizing angle in 8 nozzles. Nozzle 5 has the minimum range of $4.3 \mathrm{~m}$ and the smallest flow of $6.67 \mathrm{~L} / \mathrm{min}$. But the percentage of respirable dust being captured is $77.11 \%$ and is smaller than nozzle 6 and nozzle 8 . The nozzle 3 and 4 are the third kinds of nozzles, and the atomizing effect is the worst.
In order to verify the dust reduction effect of nozzles, the experiment of spray dust reduction was done with the water pressure of $8 \mathrm{Mpa}$ and fan rotate speed of $300 \mathrm{r} / \mathrm{min}$. The samples with different particle sizes were prepared in order to study the dust reduction effect on different particle sizes dust. In the experiment, the particle size and distribution of coal dust were analyzed by using Winner3001 dry powder laser, and the dust concentration was measured by AKFC92A dust instrument.

By setting measured in the closed test chamber outlet at the type of AKFC-92A dust instrument were determined in $8 \mathrm{Mpa}$ pressure and rotate speed of fan $300 \mathrm{r} / \mathrm{min} 8 \mathrm{kinds}$ of nozzle spray dust dust concentration, obtained by calculating the 8 kinds of nozzle spray dust fall efficiency are shown in Table 3.

TABLE 3 THE SPRAY DUST REMOVAL EFFICIENCY OF 8 NOZZLES WITH THE PRESSURE OF 8MPA AND FAN ROTATE SPEED OF 300R/MIN

\begin{tabular}{|c|c|c|}
\hline \multirow{2}{*}{ Nozzle number } & \multicolumn{2}{|c|}{ Dust removal rate/\% } \\
\cline { 2 - 3 } & Total dust & Respirable dust \\
\hline Nozzle1 & 42.71 & 35.87 \\
\hline Nozzle2 & 39.21 & 32.39 \\
\hline Nozzle3 & 50.37 & 46.61 \\
\hline Nozzle4 & 47.32 & 41.71 \\
\hline Nozzle5 & 56.30 & 51.21 \\
\hline Nozzle6 & 63.56 & 59.78 \\
\hline Nozzle7 & 60.72 & 56.17 \\
\hline Nozzle8 & 65.82 & 61.70 \\
\hline
\end{tabular}

From Table 3 it is can be seen that the ranking of dust removal is: nozzle $8>$ nozzle > nozzle $7>$ nozzle 5 nozzle $3>$ nozzle 4 . The total dust and call dust reduction rate of nozzle 8 reached $65.82 \%$ and $61.70 \%$ respectively, those of nozzle 6 reached $63.56 \%$ and $59.78 \%$ respectively, and those of nozzle 5 reached $56.30 \%$ and $51.21 \%$ respectively, which are lower than those of nozzle 6 and nozzle 8. Therefore, considering the comprehensive atomization characteristics and spray dust reduction experimental results, nozzle 5 is suitable when the range is not big and the respirable dust content is small as the flow of nozzle 5 is small and the atomizing angle is big. When the respirable dust content is larger, nozzle 6 and nozzle 8 can be selected. when the desired range is larger than $5 \mathrm{~m}$ nozzle 8 can be selected, otherwise nozzle 6 can be selected.

\section{RESEARCH ON SPRAYING AND NEGATIVE PRESSURE SECONDARY DUST REMOVING DEVICES}

According to the field measured data, it is shown that the dust particle sizes of $10 \%$ dust samples were below $7 \mu \mathrm{m}$, and cumulative distribution range of dust samples less than 8 $\mu \mathrm{m}$ is $12.1 \%-19.9 \%$. And the D90 data of dust samples is in $10.28 \mu \mathrm{m}-23.18 \mu \mathrm{m}$. The respirable dust proportion is large, and most of the dust particle size is between $8 \mu \mathrm{m}$ and $50 \mu$ m.

The dust production characteristics of coal caving operation in 3top1110 fully mechanized coal caving working face of Gao Zhuang coal mine: produce dust intermittently; 
under the action of gravity, wind and dust collisions dust not only spread in horizontal direction of workface, but spread towards the outlet in the vertical direction. The trend of spreading to the bracket back is larger, and the respirable dust occupies a certain proportion.

Combining spraying and negative pressure secondary dust reduction mechanism, dust production characteristics in coal caving operation and characteristics of optimized nozzle, and research work of coal spraying and negative pressure secondary dust removing devices in coal caving operation have been researched, which are composed of I and II and are shown in Fig. 5 (a), (b).

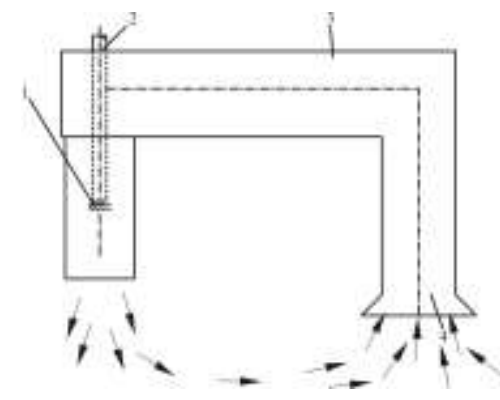

(a)

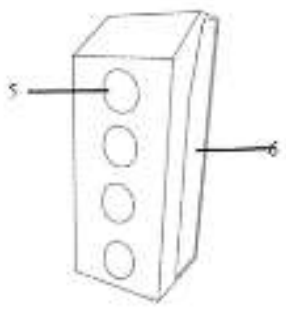

(b)

1-Spray; 2-Inlet pipe; 3-Dust collector; 4-Horn mouth; 5-Spray; 6Dust collector

Fig.5 Spraying and negative pressure secondary dust removing devices

(1)The spraying and negative pressure secondary dust removing device I in coal caving operation

The spraying and negative pressure secondary dust removing device $\mathrm{I}$ is a tube of ' $\mathrm{U}$ ' shape. Each mounting is equipped with one device with 3 nozzles, which is installed in the four link rear connecting rod of hydraulic support. The type of nozzles is nozzle 5. The device is mainly used for trapping dust of coal discharging port. Under the action of the high pressure water, the water mist is sprayed to the coal discharging port for reducing the dust. Also, as air with dust is sucked into the other end of the pipe with the water pressure, the dust concentration is reduced and the dust diffusion can be avoided to some extent.

(2)The spraying and negative pressure secondary dust removing device II in coal caving operation

The coal discharging port is installed with two spray negative pressure secondary dust removing devices II, which are respectively arranged on both sides of the coal discharging port. The device II consists of a suction mouth and four nozzles, mainly used for trapping dust near the coal dust discharging port and the dust migrating to the outlet in the role of air flow. The types of four sprays are nozzle 8, nozzle 8 , nozzle 6 , nozzle 6 from top to down. The spays point to the exit end and they can capture the dust from the coal caving operation from the upwind side.
Dust concentration and dust reduction rate of each measuring point of the working face before and after the spraying negative pressure secondary coal reducing device in coal caving operation is used are shown in Table4.

TABLE 4 DUST CONCENTRATION AND DUST REDUCTION RATE OF EACH MESURING POINT OF THE WORKING FACE BEFORE AND AFTER THE SPRAYING NEGATIVE PRESSURE SECONDARY COAL REDUCING DEVICE IN COAL CAVING OPERATION

\begin{tabular}{|c|c|c|c|c|c|c|c|}
\hline \multirow[t]{2}{*}{ NO. } & \multirow[t]{2}{*}{ Dust } & \multicolumn{2}{|c|}{$\begin{array}{l}\text { Total dust } \\
\text { concentration/ } \\
\left(\mathrm{mg} / \mathrm{m}^{3}\right)\end{array}$} & \multicolumn{2}{|c|}{$\begin{array}{l}\text { Respirable dust } \\
\text { concentration/ } \\
\left(\mathrm{mg} / \mathrm{m}^{3}\right)\end{array}$} & \multirow{2}{*}{$\begin{array}{c}\text { Reduction } \\
\text { rate of } \\
\text { total dust }\end{array}$} & \multirow{2}{*}{$\begin{array}{l}\text { Reduction } \\
\text { rate of } \\
\text { respirable } \\
\text { dust }\end{array}$} \\
\hline & & before & after & before & after & & \\
\hline $1 \#$ & coal & 300 & 33.3 & 180 & 62.7 & 0.88 & 0.65 \\
\hline $2 \#$ & coal & 290 & 35.7 & 160 & 69.5 & 0.87 & 0.56 \\
\hline $3 \#$ & coal & 200 & 31.2 & 120 & 44.4 & 0.84 & 0.63 \\
\hline 4\# & coal & 160 & 18.1 & 90 & 38.7 & 0.88 & 0.57 \\
\hline $5 \#$ & coal & 130 & 19.2 & 76 & 31.9 & 0.85 & 0.58 \\
\hline $6 \#$ & coal & 100 & 13.5 & 60 & 22.2 & 0.86 & 0.63 \\
\hline 7\# & coal & 60 & 12.1 & 44 & 18.3 & 0.79 & 0.58 \\
\hline
\end{tabular}

From Table 4 it is known that : when the dust removal devices are not used, the highest dust concentration of $3^{\text {top }} 1110$ working face reached $300 \mathrm{mg} / \mathrm{m} 3$ and $180 \mathrm{mg} / \mathrm{m} 3$, respectively. The dust concentration was decreased greatly after using the dust removal devices. The total dust removal rate is $79 \% \sim 88 \%$, and the respirable one is $56 \% \sim 65 \%$.

\section{CONCLUSIONS}

(1) The coal dust production regulations in coal caving operation are simulated by the software of FLUENT, and the optimum wind speed was determined of $3 \mathrm{~m} / \mathrm{s}$.

(2) Considering the influence of wind speed and dust source mass flow, according to the numerical simulation data, the paper gets the fitting function of dust concentration distribution about the dust near the dust production source in coal caving operation, which laid the foundation to take further measures of reducing dust .

(3)Through the jet characteristic experiment and spray dust reduction experiment of nozzles, the preferable nozzles are determined. Combining the dust production regulation in coal caving operation and the characteristics of nozzles, the spraying and negative pressure secondary dust control devices are studied. The devices are applied in 3top 1110 working face, the total dust reduction rate is $79 \% \sim 88 \%$, and the respirable dust reduction rate is $56 \% \sim 65 \%$.

\section{ACKNOWLEDGMENT}

In this paper, the research was sponsored by the National Natural Science Foundation of China (Project No. 51474139), the Key research and development plan of Shandong Province (Project No. 2017GSF220016), the First-class discipline special plan of mining engineering (Project No. 01AQ02603), and the Shandong Natural Science Foundation (Project No. ZR2016EEP02). 


\section{REFERENCES}

[1] Yang Shenglai.Numerical simulation of 3-dimensional dust distribution on long wall coal faces[J]. China Safety Science Journal, 2001, 11(4): 61-64.

[2] Liu Yi, Jiang Zhongan, Cai Wei, et al. Numerical simulation of the dust movement rule in fully-mechanized coal faces[J]. Journal of University of Science and Technology Beijing, 2007,29(4): 351-353.

[3] Zhao Zhenbao, Zhai Huibing, Wang Feng. Numerical Simulation and Experiment on the Dust Movement at Top Caving Mining Face[J]. Transactions of Beijing Institute of Technology, 2008, 28(12):11131116.

[4] Niu Wei, Jiang Zhongan, Wang Xiaozhen, et al. Numerical simulation of distribution regularities of dust concentration in fully mechanized top-coal caving face[J]. China Mining Magazine, 2008, 17(12): 77-80.

[5] Wei Chuanguang. Research on dust distribution and moving law in the underground of Lu'an Mine[D]. Beijing: University of Science and Technology Beijing, 2009.

[6] Du Cuifeng, Wang Hui, Jiang Zhong'an, et al . Numerical simulations of dust distribution in a fully mechanized excavation face with far-pressing-near-absorption ventilation[J].Journal of University of Science and Technology Beijing, 2010, 32( 8) : 957-962.

[7] Zhou Gang, Cheng Weimin, Cheng Lianjun, et al. Numerical simulation and its application of dust concentration spatial distribution regularities in fully-mechanized caving face $[\mathrm{J}]$. Journal of China Coal Society, 2010, 35( 12) : 2094-2099.

[8] Niu Wei, Jiang Zhongan, Liu Yi. Numerical simulation on dust movement regularities at fully-mechanized coal faces and its utilization[J]. Journal of Liaoning Technical University: Natural Science, 2010, 29(3): 357-360.

[9] Cheng Weimin, Nie Wen, Yao Yujing et al. Numerical simulation on the flow field of swirling flow air curtain aspiration control dust in fully mechanized workface[J]. Journal of China Coal Society, 2011, 36(8):1342-1348

[10] Wang Hui, Jiang Zhongan, Du Cuifeng, et al. Field study and numerical research on dust concentration distribution in the excavation tunnel[J]. Journal of Liaoning Technical University(Natural Science,2011,30(3):345-348.

[11] Liao Xianxin, Jiang Zhongan, Niu Wei, et al. Numerical simulations of blasting dust migration with the use of Fluent in stope [J]. Journal of Safety and Environment, 2012,12(6) : 43-46.

[12] Chen Jushi, Jiang Zhongan, Yang Bin, et al. Numerical simulation of spatial dust concentration distribution regularities in crushing chamber [J]. Journal of China Coal Society,2012,37(11):1865-1870.

[13] Jiang Zhong-an, Chen Ju-shi, Wang Jing-jing, et al. Numerical simulation of dust movement regularities in belt conveyer roadway[J]. Journal of China coal society, 2012,37(4):659-663.

[14] Chen Ju-shi, Wang Yi, Jiang Zhong-an.Numerical simulation of blasting dust concentration distribution and diffusion regularities in stope[J]. Journal of China Coal Society, 2013, 38(s1):147-152.

[15] Jiang Zhong-an, Chen Ju-shi, Niu Wei, et al.Numerical simulation of dust concentration distribution regularity in a belt conveyer roadway[J].Journal of University of Science and Technology Beijing,2012,34(9):977-981.

[16] Yao Xiwen, Lu Guangli, Xu Kaili.Numerical simulation of dust generation at different procedures in steeply inclined fullymechanized caving face[J].Journal of China Coal Society, 2015, 40(2): 389-396.

[17] [Tan Cong, Jiang Zhongan, Wang Ming, etal. Similarity experiment on multi-source dust diffusion law in fully mechanized caving face[J]. Journal of China Coal Society, 2015, 40(1) :122127.

[18] Zheng Lei, Wang Chunmei, Qin Yuhong. Study of Dust Control Based on Analysis of Dust Distribution and Diffusion in Fullymechanized Face, Industrial Safety and Environmental Protection, 2015,41(1):26-28.
[19] Zhou Gang, Zhang Qi, Bai Ruonan, et al.CFD simulation of airrespirable dust coupling migration law at fully mechanized mining face with large mining height $[\mathrm{J}]$. Journal of China University of Mining \&Technology, 2016, 45(4):684-693.

[20] Nie Yao. The Study of Dust Movement Laws and the Dust Parameter Optimization of Hydraulic Supports on Fully Mechanized Mining Face[D], Xi'An University of Science and Technology, 2017.

[21] Zhang Qi. Numerical simulation study on laws of air diffusion and respirable dust pollution from micro to macro dimensions in fullymechanized mining face[D], Qingdao: Shandong University of Science and Technology, 2017.

[22] Liu Xuxu.Spray dust suppression system for hydraulic support in fully mechanized caving face[J].Coal mine safety, 2004, 35(7) : 2122.

[23] Zhai Guodong, Dong Zhifeng.Design and optimization of coal dust collector for coal injection[J].Mining safety and nvironmental protection, 2007, 34(2): 41-43.

[24] Liu Xiangsheng.Choosen and optimiation of spraying system on support for dust-laying in fully-mechanized caving face[D].Qingdao: Shangdong University of Science and Technology, 2007.

[25] Li Qi. Study on the negative-pressure absorb dust device used at the coal draw point of the hydraulic support on the fully-mechanized caving mining face [D]. Taiyuan:Taiyuan University of Technology, 2008 .

[26] Niu Quanzhen. Study on design of mine wind-water atomizing aspirating device and flow field emulation[D]. Taiyuan:Taiyuan University of Technology, 2008.

[27] Yu Fangchao.Infrared Control Spray System Caving Face[J]. Mechanical management and development, 2010, 25(6): 107, 109.

[28] Xu Mangui, Liu Xinkai, Wen Xinqiang. Full-mechanized excavation face efficient sprinkler\&dust fall system[J].Journal of Hunan University of Science \& Technolgy(Natural Science Edition), 2015, 30(2):1-7.

[29] Nie Wen, Liu Yanghao, Cheng Weimin, et al. Dust removal technology of eject spraying between hydraulic supports on fully mechanized mining face[J]. Journal of Central South University (Science and Technology), 2015,46(11):4384-4390.

[30] Jiang Zhongan, Wang Ming, Chen Jushi, Lin Menglu. Atomization characteristics and dust suppression mechanism of a gas-water nozzle[J]. Journal of Harbin Institute of Technology, 2017, 49(2):151157.

[31] Guo Jie, Xing Shijun, Song Xianming, et al. Automatic spray dust removal technology of hydraulic support in high yield and high efficiency fully mechanized caving face[J]. Mining safety and environmental protection, 2004, 31(4) : 68-70, 72.

[32] Wang Xuyou, Liu Jian, Xie Huadong, et al.Application of automatic spray dust suppression technology in fully mechanized caving face[J].China Coal, 2005, 12(31):46-47, 49.

[33] Zhou Gang.Research of theory about dust prevention by water-cloud and relevant techniques for fully-mechanized caving coal face[D]. Qingdao: Shangdong University of Science and Technology, 2007.

[34] Xie Junsheng, Li Dewen.Study on the on-line monitoring technology of dust and dust in fully mechanized caving face[J]. Mining safety and environmental protection 2010, 37(4):53-55.

[35] Song Jianguo. Technology and application of high pressure spray dust suppression in fully mechanized face $[\mathrm{J}]$. Coal engineering, 2010,(10):43-45.

[36] Wang Pengfei, Liu Ronghua, Tang Meng, et al. Experimental study on atomization characteristics and dust suppression efficiency of high-pressure spray in underground coal mine[J]. Journal of China coal society, 2015, 40(9) : 2124-2130.

[37] Qin Botao, Zhou Qun, Li Xiulei, et al. Synergistic technology between surfactant and magnetized water for efficient dust control in under-ground coal mines[J].Journal of China Coal Society, 2017, 42( 11) : 2900-2907. 